\title{
CHK1 Inhibitor MK-8776
}

National Cancer Institute

\section{Source}

National Cancer Institute. CHK1 Inhibitor MK-8776. NCI Thesaurus. Code C79867.

An agent targeting cell cycle checkpoint kinase 1 (Chk1) with potential radiosensitization and chemosensitization activities. Chk1 inhibitor MK-8776 specifically binds to and inhibits Chk1, which may result in tumor cells bypassing Chk1-dependent cell cycle arrest in the S and G2/M phases to underg o DNA repair prior to entry into mitosis; tumor cells may thus be sensitized to the DNA-damaging effects of ionizing radiation and alkylating chemotherapeutic agents. Chk1 is an ATP-dependent serine-threonine kinase that in response to DNA damage phosphorylates cdc25 phosphatases, resulting in inhibitory tyrosine phosphorylation of CDK-cyclin complexes and cell cycle arrest. 